\title{
Escherichia coli and Staphylococcus aureus contaminations of carrots sold within Zaria, Nigeria and their antibiotic susceptibility profiles
}

\begin{abstract}
Carrots (Daucus carota) are root vegetable containing carotene, vitamins and mineral salts. Carrots maybe purple, red, white or yellow in color depending on their varieties and can be eaten fresh, mixed in salad or cooked. Carrots are prone to faecal contamination and often subjected to poor/rough handling in Nigeria. Upon purchase, many people consume them without proper washing. Hence, instead of serving nutritive purposes, they may turn to be a source of food poisoning/infections. Escherichia coli have caused a number of diarrheal diseases and Staphylococcus aureus is an important agent of food poisoning. Forty (40) fresh carrot samples were randomly purchased from different vendors in Zaria metropolis. Then, $10 \mathrm{~g}$ of epidermal (layer) scrapings of each sample was aseptically collected, homogenized in $90 \mathrm{ml}$ of buffered peptone water and serially diluted. From $10^{-4}$ dilution, $0.1 \mathrm{ml}$ was spread-plated on EMB and MSA plates, followed by $24 \mathrm{hrs}$ incubation at $37^{\circ} \mathrm{C}$. Characteristic colonies of E. Coli and S. Aureus were Gram-stained and biochemically identified. A susceptibility testing of the isolates to some selected antibiotics was performed using disc diffusion method. Twenty (20) out of the 40 carrot samples were positive for $E$. Coli $(50.0 \%)$, whereas $S$. Aureus were isolated from 26 samples $(65.0 \%)$ with a total mean staphylococcal count of $4.3 \times 10^{5} \mathrm{CFU} / \mathrm{g}$. All the Escherichia coli isolates were susceptible to Streptomycin $(30 \mu \mathrm{g})$ and Tarivid $(10 \mu \mathrm{g})$, but Septrin $(30 \mu \mathrm{g})$ and Amoxicillin $(30 \mu \mathrm{g})$ had the least activities against them. Staphylococcus aureus isolates were most susceptible to Ciprofloxacin $(10 \mu \mathrm{g})$, followed by Gentamycin $(10 \mu \mathrm{g})$ and Streptomycin $(30 \mu \mathrm{g})$, but resistant to Ampiclox $(30 \mu \mathrm{g})$ and Amoxicillin $(30 \mu \mathrm{g})$
\end{abstract}

Keywords: Escherichia coli, Staphylococcus aureus, susceptibility, antibiotic, carrot, contamination, zaria, nigeria
Volume I Issue 4 - 2017

\author{
Henry Gabriel Bishop, Grace Onyowoicho \\ Okwori \\ Department of Microbiology, Ahmadu Bello University, Nigeria
}

Correspondence: Henry Gabriel Bishop, Department of Microbiology, Faculty of Life Sciences, Ahmadu Bello University, Zaria, Nigeria, Tel +2348 17635762 6,

Email gabrielhenrybishop@gmail.com

Received: October 20, 2017 | Published: November 20, 2017
Abbreviations: CMKT, community market; CLSI, clinical and laboratory standards institute; $\mathrm{CFU} / \mathrm{g}$, colony forming unit per gram: EMB, eosin methylene blue; G, gram; MSA, mannitol salt agar; $\mu \mathrm{g}$, microgram; MLS, milliliters; MHA, muller-hinton agar; PZ, pz area; SBMKT, sabon-market

\section{Introduction}

Carrots are one of the most commonly used vegetables with nutritive value of vitamins (A, B, C, D, K) and mineral (calcium, potassium, phosphorus, sodium, iron). They contain carotenoids and antioxidants, which protect humans from cancers, strokes and cardiovascular diseases. ${ }^{1}$ They contain about $88 \%$ water, $7 \%$ sugar, $0.2 \%$ fat, $1 \%$ each of protein, fiber and ash $^{3}$ and no starch. ${ }^{4}$ All vegetables are soft and prone to nematodal, insect, bacterial, fungal or chemical attack. Unsuitable temperature, contaminated materials and poor sanitation enhance their deterioration. ${ }^{5}$ Microbial contaminations of vegetables could result from soil, water, air, insects, animals or human contact. Bacterial attacks can occur during early growth to maturity on the field, distribution and sale or storage at home. ${ }^{1,2}$ Faecal contamination of vegetables with Escherichia coli (E. Coli) and Salmonella spp had been reported ${ }^{6}$ mainly due to contaminated irrigation water. ${ }^{7}$ E. Coli causes diarrhoeal diseases via production of enterotoxin or cytotoxin, or plasmid-mediated virulence factors. ${ }^{8}$ Staphylococcus aureus (S. Aureus) causes food poisoning due to contamination of vegetable during handling or from utensils. ${ }^{5}$ Postharvest contamination of vegetable from faeces, human handling, harvesting tools, transport vessels, wild and domestic animals, insects, dust, wash water, ice, transport vehicles, and processing tools must be checked. ${ }^{9}$ Since vegetables are increasingly been linked to food borne outbreaks, ${ }^{7}$ this research aimed to identify contaminations of carrots by $E$. Coli and S. Aureus, and challenge them with antibiotics, as they are capable of causing diarrhoea/food poisoning after ingestion.

\section{Materials and methods}

\section{Study area}

The study was conducted in Zaria. Four sampling locations where carrots were mostly sold were randomly selected, which included Samaru Market, PZ Area, A.B.U. Community Market and Sabon-Gari Market.

\section{Collection and processing of carrot samples}

In all, 40 fresh carrot samples were collected by randomly purchasing 10 samples from different vendors in each of the four sampling locations in Zaria. The samples were placed in clean separate polythene bags and transferred immediately in cool containers to the laboratory. All the carrots samples were analyzed within 1-2hours after the sampling. Sterilized blades were used to aseptically scrape $10 \mathrm{~g}$ of the epidermal layer (i.e. phyllosphere) from each carrot sample. Then $10 \mathrm{~g}$ of each carrot scrapings was added to $90 \mathrm{ml}$ of buffered peptone water and homogenized. Serial dilutions were made to obtain $10^{-1}, 10^{-}$ ${ }^{2}, 10^{-3}$, and $10^{-4}$ dilutions. 


\section{Cultural and biochemical isolation of E. Coli and S. Au- reus}

From the $10^{-4}$ dilution, $0.1 \mathrm{ml}$ each was spread-plated unto EosinMethylene Blue (EMB) and Mannitol Salt Agar (MSA) plates and incubated at $37^{\circ} \mathrm{C}$ for $24 \mathrm{hrs}$. Characteristic colonies were purified and Gram-stained. Staphylococcal count (of colony forming units, i.e. $\mathrm{CFU} / \mathrm{g}$ ) was determined from the MSA plates. The pure cultures were stored on Nutrient Agar at $4^{\circ} \mathrm{C}$ for further biochemical tests. Suspected E. Coli were biochemically confirmed using indole, Methy red, Voges Proskauer, and citrate utilization tests. But mannitol fermentation, catalase and coagulase tests were used to confirm $S$. Aureus as suggested by Cheesbrough. ${ }^{10}$

\section{Antibiotic Susceptibility testing of isolates}

The isolates were challenged with some panels of selected antibiotics to determine their susceptibility patterns using agar disc diffusion method on Muller-Hinton Agar (MHA). The inocula were prepared by turbidity standard of 0.5 McFarland. ${ }^{10}$ Susceptibility patterns were determined using the Clinical laboratory standards. ${ }^{11}$

\section{Results}

Out of 40 carrot samples, 26 were contaminated with S. Aureus, with a prevalence of $65.0 \%$. The occurrence of $S$. Aureus was higher, where 20 of the carrot samples were contaminated giving a prevalence of $50.0 \%$. There was a co-contamination of $32.5 \%$, where each carrot sample was contaminated with the two pathogens at the same time (Table 1). Based on sampling locations, the highest carrot contamination with $S$. Aureus occurred on samples obtained from PZ area $(80.0 \%)$ followed by those from Sabon-Gari Market. Whereas, $E$. Coli had $70 \%$ occurrence on carrots obtained from Sabon-Gari Market and Samaru Market each (Table 2). The highest staphylococcal count of carrot samples occurred on samples obtained from Sabon-Gari and Samaru Markets, but the overall mean occurrence in Zaria, Nigeria was $4.3 \times 10^{5} \mathrm{CFU} / \mathrm{g}$. Even though carrots samples from Samaru Market had the least prevalence of S. Aureus contamination (Table 1), they rather had a higher staphylococcal count in Table 2. Generally, the areas with highest prevalence of these pathogens did not coincide with those of highest staphylococcal counts on the carrots (Table 2) (Table 3).

Table I Prevalence of E. Coli and S. Aureus and their co-contaminations on carrots sold in Zaria, Nigeria

\begin{tabular}{lll}
\hline Pathogen & Number (\%) positive & Number (\%) negative \\
\hline E. coli & $20(50.0)$ & $20(50.0)$ \\
S. aureus & $26(65.0)$ & $14(35.0)$ \\
Co-contaminations & $13(32.5)$ & $27(67.5)$
\end{tabular}

Table 2 Occurrences of E. Coli and S. Aureus based on sampling locations in Zaria, Nigeria

\begin{tabular}{llll}
\hline Sampling location & Number of samples examined & $\begin{array}{l}\text { Number (\%) containing } \\
\text { E. coli }\end{array}$ & $\begin{array}{l}\text { Number (\%) cont\$aining } \\
\text { S. aureus }\end{array}$ \\
\hline SMKT & 10 & $7(70)$ & $5(50)$ \\
PZ & 10 & $2(20)$ & $8(80)$ \\
CMKT & 10 & $4(40)$ & $6(60)$ \\
SBMKT & 10 & $7(70)$ & $7(70)$ \\
Total & 40 & $20(50.0)$ & $26(65.0)$ \\
\hline
\end{tabular}

Table 3 Staphylococcal count of epidermal scrapings of carrot samples sold in Zaria, Nigeria

\begin{tabular}{lllll}
\hline $\begin{array}{l}\text { Dilution } \\
\text { factor }\end{array}$ & $\begin{array}{l}\text { Sample } \\
\text { location }\end{array}$ & $\begin{array}{l}\text { No. } \\
\text { tested }\end{array}$ & $\begin{array}{l}\text { Range Of staphylococcal } \\
\text { count(Cfu/G) }\end{array}$ & $\begin{array}{l}\text { Mean staphylococcal count } \\
\text { (Cfu/G) }\end{array}$ \\
\hline & SMKT & 10 & $2.0 \times 105-7.0 \times 10^{5}$ & $4.8 \times 10^{5}$ \\
& PZ & 10 & $2.0 \times 105-6.0 \times 10^{5}$ & $3.9 \times 10^{5}$ \\
104 & CMKT & 10 & $1.3 \times 105-9.0 \times 10^{5}$ & $3.3 \times 10^{5}$ \\
& SBMKT & 10 & $3.0 \times 105-8.0 \times 10^{5}$ & $4.9 \times 10^{5}$ \\
Total & - & 40 & - & $4.3 \times 10^{5}$ \\
\hline
\end{tabular}

SMKT, Samaru Market; CMKT, A.B.U. Community Market; SBMKT, Sabon-Market; PZ , PZ area

From a panel of 10antibiotics of which 20 isolates of E. Coli were challenged with, $100 \%$ susceptibility to Streptomycin $(30 \mu \mathrm{g})$ and Tarvid $(10 \mu \mathrm{g})$ was observed. Also, $90 \%$ susceptibility to Chloramphenicol $(30 \mu \mathrm{g})$ and Gentamycin $(10 \mu \mathrm{g})$ were recorded. On the other hand, E. Coli had the highest resistance to Augmentin $(30 \mu \mathrm{g})$ and Amoxicillin $(30 \mu \mathrm{g})$ (Table 4). Similarly, 26 isolates of $S$.
Aureus were challenged with a panel of 10 antibiotics. The highest susceptibility was $92.3 \%$ to Ciprofloxacin $(30 \mu \mathrm{g})$, following by $88.5 \%$ to Gentamycin $(10 \mu \mathrm{g})$. However, the highest resistance of $S$. Aureus was $84.6 \%$ to both Amoxicillin $(30 \mu \mathrm{g})$ and Ampiclox $(30 \mu \mathrm{g})$ as indicated in (Table 5). 
Table 4 Antibiotic susceptibility patterns for Escherichia coli isolates from carrot samples sold in Zaria, Nigeria

\begin{tabular}{llll}
\hline Antibiotics/ Disc potency $(\boldsymbol{\mu g})$ & Number(\%) susceptible & Number(\%) intermediate & Number (\%) resistant \\
\hline Augmentin (30) & $7(35.0)$ & $3(15.0)$ & $10(50.0)$ \\
Ciprofloxacin (10) & $15(75.0)$ & $3(15.0)$ & $2(10.0)$ \\
Amoxicillin (30) & $8(40.0)$ & $2(10.0)$ & $10(50.0)$ \\
Chloramphenicol (30) & $18(90.0)$ & $I(5.0)$ & $I(5.0)$ \\
Streptomycin (30) & $20(100.0)$ & $0(0.0)$ & $0(0.0)$ \\
Pefloxacin (30) & $13(65.0)$ & $5(25.0)$ & $2(10.0)$ \\
Septrin (30) & $6(30.0)$ & $7(35.0)$ \\
Gentamycin (10) & $7(35.0)$ & $I(5.0)$ & $I(5.0)$ \\
Tarivid (10) & $18(90.0)$ & $0(0.0)$ & $0(0.0)$ \\
Sparfloxacin (10) & $20(100.0)$ & $2(10)$ & $2(10)$ \\
\hline
\end{tabular}

$\mathrm{n}=20$ isolates

Table 5 Antibiotic susceptibility patterns of S.Aureus isolates from carrot samples sold in Zaria, Nigeria

\begin{tabular}{|c|c|c|c|}
\hline Antibiotics/ Disc potency $(\mu \mathrm{g})$ & Number(\%) susceptible & Number(\%) intermediate & Number (\%) resistant \\
\hline Pefloxacin (10) & $2 \mathrm{I}(80.8)$ & $4(15.4)$ & $\mathrm{I}(3.8)$ \\
\hline Streptomycin (30) & $22(84.6)$ & $4(15.4)$ & $0(0.0)$ \\
\hline Erythromycin (10) & $16(61.5)$ & $3(11.5)$ & $7(26.9)$ \\
\hline Zinnacef (20) & 14(53.8) & $2(7.7)$ & $10(38.5)$ \\
\hline Septrin (30) & $13(50.0)$ & $2(7.7)$ & II(42.3) \\
\hline Gentamycin (10) & $23(88.5)$ & $0(0.0)$ & $3(11.5)$ \\
\hline Amoxicillin (30) & $4(15.4)$ & $0(0.0)$ & $22(84.6)$ \\
\hline Rocephin (25) & $2 \mathrm{I}(80.8)$ & $2(7.7)$ & $3(11.5)$ \\
\hline Ciprofloxacin (10) & $24(92.3)$ & $\mathrm{I}(3.8)$ & $\mathrm{I}(3.8)$ \\
\hline Ampiclox (30) & $2(7.7)$ & $2(7.7)$ & $22(84.6)$ \\
\hline
\end{tabular}

\section{$\mathrm{n}=26$ isolates}

\section{Discussion}

Though there are a lot of health benefits from vegetable consumption and promoting increased demands on these produce, ${ }^{12}$ they are also not without consequences if hygienic practices are not observed. The major threats carrots pose on consumers all over the world (and Nigeria in particular) is the risk of infections/food poisoning. Some of these consumers do little or no further washing/ processing of purchased carrots before consumption; hence, they stand at increased risks of infections. ${ }^{12}$ Heaton and Jones have emphasized on potential risks of infections and outbreaks following the consumption of vegetables. E. Coli can be transmitted to humans via foods and vegetables contaminated with animal faeces. Such commonly implicated vegetable include carrots, lettuce, radish sprout, alfalfa sprout, potatoes, spinach, green onions, cabbage, pepper, cucumber and so on. ${ }^{13}$ Of the two pathogens examined, $S$. Aureus contamination of carrots occurred higher than E. Coli. Though $S$. Aureus is a normal flora of the skin and nares, it can also cause a number of infections. Human contact and carriers of $S$. Aureus help in its transfer unto vegetables, especially those vegetables hawked or exposed along roadsides. Outbreaks caused by Staphylococcus have implicated vegetables like carrots, alfalfa sprouts, lettuce, parsley, radish and onion sprouts as vehicles. ${ }^{9}$ Carrots ready-for-consumption in this part of the world are majorly exposed along roadsides or hawked while exposed in streets or markets. Buyers touch the carrots severely to select their choices. This behaviour increases the transfer of $S$. Aureus from contaminated hands unto the carrots sold.

More so, the consumption of vegetables like carrots is linked with increased risks of enteropathogenic infections ${ }^{12}$ by E. Coli, S. Aureus and Salmonella enterica with consequent foodborne outbreaks due to them. ${ }^{15}$ The occurrences of $E$. Coli especially E. coli $\mathrm{O} 157: \mathrm{H} 7^{13,14}$ and $S$. Aureus $^{16}$ have been reported in ready-to-eat raw salad. There is an inadequate awareness of the plant-microbe interactions, epiphytic and immigrant micro-organism on leaves and phyllosphere of vegetables ${ }^{12}$ which is prompting the continuous spread of pathogens to humans. Many sources of contamination of vegetables include soil, faeces, water for irrigation, dust, insects, inadequately composted manure, 
wild or domestic animal wastes, and human handling. ${ }^{9}$ The use of inadequately treated water for irrigation purpose in carrot cultivation could increase the spread of E. Coli and other entero-pathogens. ${ }^{12}$ Such water is obtained from shallow streams exposed to refuse-dumping and human/animal wastes. Other irrigation farms use untreated night soil as manure or organic fertilizer, ${ }^{17}$ wastes from abattoirs. ${ }^{18}$ Sewage and surface run-offs ${ }^{12}$ can contaminate fresh vegetables. The presence of infections or outbreaks following consumption of vegetables like carrots can affect the demand of such produce because consumers are rational in their choices. This will also affect the income of local farmers and the economy at large. It is important to adequately wash carrots with clean water and peel off the epidermal layers before consumption. This practice will help to remove pathogenic organisms that have adhered to the carrots. Safe and treated water should be advocated for vegetable irrigation farming. The unhygienic hawking of carrots or roadside selling should be disallowed and regulations should be enforced on hygienic processing selling/distribution of carrots in the country. ${ }^{19,20}$

\section{Conclusion}

Carrots are widely and increasing being consumed in all parts of the world because they constitute an important source of nutrients. However, they are prone to so many contamination routes: from the cultivation farms, through the chains of distribution, to the final consumers. In Nigeria, carrots are often sold along roadsides or hawked in markets or streets. Some sellers used the same wash water repeatedly for the carrots sold, which are also exposed to other airborne contaminations. Bacterial contamination was evident by the presence of E. Coli and S. Aureus isolated from the epidermal (phyllosphere) scrapping of sampled carrots in Zaria, Nigeria. The prevalence of E. Coli was $50.0 \%$, but $S$. Aureus occurred higher with a prevalence of $65.0 \%$ and a mean staphylococcal count of $4.3 \times 10^{5}$ $\mathrm{CFU} / \mathrm{g}$. These pathogens can cause infections/food poisoning when contaminated carrots are consumed. After subjecting the bacterial isolates to some selected antibiotics, E. Coli were most susceptible to Streptomycin $(30 \mu \mathrm{g})$ and Tarvid $(10 \mu \mathrm{g})$, Chloramphenicol $(30 \mu \mathrm{g})$ and Gentamycin $(10 \mu \mathrm{g})$. On the other hand, the E. Coli had the highest resistance to Augmentin $(30 \mu \mathrm{g})$ and Amoxicillin $(30 \mu \mathrm{g})$. Also, the S. Aureus isolates were most susceptible to Ciprofloxacin $(30 \mu \mathrm{g})$, and Gentamycin $(10 \mu \mathrm{g})$, but mostly resistant to Amoxicillin $(30 \mu \mathrm{g})$ and Ampiclox $(30 \mu \mathrm{g})$. Hygienic practices should be observed in the cultivation and distribution of carrots. It is equally necessary to adequately wash carrots with clean water, peel off the epidermal layer and rinse again before consumption. Government can discourage the unhygienic processing/hawking of carrots and other vegetables along roadsides and streets in Nigerian through firm regulations.

\section{Acknowledgements}

We express our appreciation to members of technical staff at the Department of Microbiology, Faculty of Life Sciences, Ahmadu Bello University, Zaria, Nigeria.

\section{Conflict of interest}

The authors declare that there is no any financial or conflict of interest.

\section{References}

1. Van Duyn MAS, Pivonka E. Overview of the health benefits of fruits and vegetable consumption for the dietics professional: Selected literature. $J$ Am Diet Assoc. 2000;100(12):1511-1521.
2. Beuchat LR. Ecological factors influencing survival and growth of human pathogens on raw fruits and vegetables. Microbes Infect. 2002;4(4):413-423.

3. Sharma KD, Karki S, Thakur NS, et al. Chemical composition, functional properties and processing of carrot- a review. J Food Sci Technol. 2012;49(1):22-32.

4. Rubatsky VE, Quiros CF, Siman PW. Carrots and related vegetable Umbelliferae. UK: CABI Publishing; 1999.

5. Gadaga TH, Nyanga LK, Mulukumira AN. The occurrence, growth and control of pathogen in African fermented foods. African Journal of Food Agriculture, Nutrition and Development. 2004;4(1):1-5.

6. Lund BM. Bacterial associated with fresh and stored fruit and Vegetables advanced cause in Food Microbiology. University of survey, AFC Food Research Institute, Conley lane, Norwich, England; 1983.

7. Erickson MC. Microbial risks associated with cabbage, carrots, celery, onions, and Deli salads made with these produce items. Comprehensive Reviews in Food Science and Food Safety. 2010;9(6):602-619.

8. Lenette EH, Speulding EH, Trauant JP. Manual Clinical Microbiology. 2nd ed. ASM, Washington DC, USA; 1995.

9. Buck JW, Walcott RR, Beuchat LR. Recent trends in microbiological safety of fruits and vegetables. Plant Health progress. 2003.

10. Cheesbrough M. District Laboratory Practice in Tropical Countries Part II. $2^{\text {nd }}$ ed. Cambridge University Press, Cambridge, UK; 2006. p. $1-442$.

11. Clinical and Laboratory Standards Institute (CLSI). Performance Standards for Antimicrobial Susceptibility Testing; Twenty-Fourth Informational Supplement. CLSI document M100-S24. Wayne, PA: Clinical and Laboratory Standards Institute, Pennsylvania, USA; 2014.

12. Heaton JC, Jones K. Microbial contamination of fruit and vegetables and the behavior of enter pathogens in the phyllosphere: a review. $J \mathrm{Appl}$ Microbiol. 2008;104(3):613-626.

13. Roever CD. Microbiological safety evaluations and recommendations on fresh produce. Food Control. 1998;9(6):321-347.

14. Islam M, Doyle MP, Phatak SC, et al. Survival of Escherichia coli O157:H7 in soil and on carrots and onions grown in fields treated with contaminated manure composts or irrigation water. Food Microbiology 2005;22:63-70.

15. Mritunjay SK, Kumar V. Potential hazards of microbial contamination associated with raw eaten salad vegetables and fresh produces. MiddleEast Journal of Scientific Research . 2015;23(24):741-749.

16. Abdelnoor AMR, Batshoun R, Roumani BM. The bacterial flora of fruits and vegetables in Lebanon and the effect of washing on the bacterial content. Zentralbl Bakteriol Mikrobiol Hyg B. 1983;177:342-349.

17. Natvig EE, Ingham SC, Ingham BH, et al. Salmonella enterica serovar Typhimurium and Escherichia coli contamination of root and leaf vegetables grown in soils with incorporated bovine manure. Applied and Environmental Microbiology. 2002;68(6):2737-2744.

18. Avery LM, Killham K, Jones DL. Survival of E. coli O157: H7 in organic wastes destined for land application. Journal of Applied Microbiology. 2005;98(4):814-822.

19. Krinsky NI, Johnson EJ. Carotenoid actions and their relations to health and diseases. Mol Aspects Med. 2005;26:459-516.

20. Saeed AY, Mazin H, Saadi AA, et al. Detection of Escherichia coli O157 in Vegetables. IOSR Journal of Agriculture and Veterinary Science. 2013;6(2):16-18. 